\title{
Silencing of $\beta 1$ integrin regulates airway remodeling by regulating the transcription of SOCE-associated genes in asthmatic mice
}

\author{
CHEN QIU ${ }^{1}$, WENWEN LIU ${ }^{1}$, FEI SHI ${ }^{1}$, MENGJIE FEN ${ }^{1}$, LILI REN ${ }^{2}$ and HUI QI $^{2}$ \\ ${ }^{1}$ Department of Respiratory Medicine; ${ }^{2}$ Clinical Medical Research Center, The Second Clinical College, \\ Jinan University, Shenzhen, Guangdong 518001, P.R. China
}

Received June 14, 2016; Accepted April 27, 2017

DOI: $10.3892 / \mathrm{mmr} .2017 .6863$

\begin{abstract}
The incidence of asthma is increasing globally; however, current treatments are only able to cure a certain proportion of patients. There is an urgent need to develop novel therapies. $\beta 1$ integrin serves a role in the pathophysiology of asthma through the development of airway remodeling. The aim of the present study was to investigate silencing of the $\beta 1$ integrin gene in pre-clinical models of allergic asthma. BALB/c mice were sensitized with ovalbumin through intraperitoneal injection and repeated aerosolized ovalbumin. A short hairpin RNA of the $\beta 1$ integrin gene was designed and transfected into mouse models of asthma in vivo, in order to evaluate whether silencing of the $\beta 1$ integrin gene affects airway smooth muscle cell proliferation and inflammation by regulating the mRNA expression of store-operated $\mathrm{Ca}^{2+}$ entry (SOCE)-associated genes. Silencing the $\beta 1$ integrin gene may downregulate $\beta 1$ integrin mRNA while not statistically decreasing $\alpha$-smooth muscle actin gene expression and airway smooth muscle thickness. $\beta 1$ integrin silencing was able to downregulate the transcription of SOCE-associated genes to normal levels, including calcium release-activated calcium modulator 1 and short transient receptor potential channel member 1, but not stromal interaction molecule 1, in asthma. Silencing of the $\beta 1$ integrin gene additionally maintained nuclear factor of activated T-cells cytoplasmic 1 gene expression, and inflammatory cytokines interleukin- 4 and interferon- $\gamma$ at normal levels. The results of the present study provide evidence to suggest that silencing of the $\beta 1$ integrin gene may be of therapeutic benefit for patients with asthma.
\end{abstract}

Correspondence to: Dr Chen Qiu, Department of Respiratory Medicine, The Second Clinical College, Jinan University, 1017 Dongmen Beilu, Luohu, Shenzhen, Guangdong 518001, P.R. China

E-mail: toxinyang@163.com

Key words: asthma, silencing $\beta 1$ integrin gene, store-operated $\mathrm{Ca}^{2+}$ entry, airway smooth muscle cell proliferation, inflammatory cytokines

\section{Introduction}

Asthma is a heterogeneous and chronic inflammatory disease that is defined by a history of respiratory symptoms and variable expiratory flow limitation (1). The dynamics of airway function are influenced by a number of distinct smooth muscles (2). $\mathrm{Ca}^{2+}$ signaling serves an important role in the cellular processes that are known to be altered in the airway smooth muscle cells (ASMCs) of subjects with asthma, including contractility, proliferation, migration and secretion of inflammatory mediators (3).

Various $\mathrm{Ca}^{2+}$ influx pathways exist in the plasma membranes of ASMCs, including voltage-gated $\mathrm{Ca}^{2+}$ channels, receptor-operated $\mathrm{Ca}^{2+}$ channels, store-operated $\mathrm{Ca}^{2+}(\mathrm{SOC})$ channels and $\mathrm{Na}^{+} / \mathrm{Ca}^{2+}$ exchangers (4). Experimental and clinical studies have demonstrated that voltage-gated $\mathrm{Ca}^{2+}$ channel blockers exert no obvious effects on the regulation of airway hyperresponsiveness (5-7); by contrast, SOC channel blockers have been demonstrated to be effective in attenuating airway hyperresponsiveness in ovalbumin-sensitized guinea pigs (8). SOC entry (SOCE) serves an important role in regulating $\mathrm{Ca}^{2+}$ signaling, and the cellular responses and hyperplasia of ASMCs (9-11).

$\mathrm{Ca}^{2+}$ influx through calcium release-activated channels (CRAC) via SOCE has been proposed to be associated with the proliferation of ASMCs (9). The knockdown of stromal interaction molecule 1 (STIM1) or calcium release-activated calcium modulator 1 (ORAI1) using small interfering RNA resulted in a decrease in SOCE in response to store depletion by histamine or thapsigargin in human ASMCs, indicating that STIM1 and ORAI1 are important contributors to SOCE in ASMCs exhibiting hyperplasia $(12,13)$. Additionally, ORAI1 has been reported to interact with short transient receptor potential channel member 1 (TRPC1) and forms a ternary complex with STIM1 in the plasma membrane $(14,15)$. TRPC1, a molecular candidate component of SOC channels, has been observed in proliferative porcine ASMCs (9). Therefore, $\mathrm{Ca}^{2+}$ influx through SOCE appears to be important for the regulation of ASMC proliferation.

Structural alterations induced by pathological repair mechanisms, termed airway remodeling, are a consequence of chronic inflammation and mechanical forces in airways exacerbated by asthma (16). $\beta 1$ integrin is widely-expressed in the airway and the expression is altered in asthma, particularly in 
ASMCs (17). $\beta 1$ integrin is associated with cell proliferation, airway and vascular remodeling, obstruction, and hyperresponsiveness (18-20). An increase in $\beta 1$ integrin expression was observed to be associated with inflammation, fibrosis and airway hyperresponsiveness (20-22). Short hairpin (sh)RNA targeting $\beta 1$ integrin markedly promoted cellular apoptosis, and inhibited cell proliferation, migration, and interleukin (IL)-6 and IL-8 secretion in vitro (19).

It was hypothesized that silencing of the $\beta 1$ integrin gene may inhibit ASMC proliferation and allergic inflammation by attenuating the transcription of SOCE-associated genes. The present study assessed ASM thickness, and the expression of six mRNAs and two inflammatory cytokines. The regulatory effect of silencing the $\beta 1$ integrin gene may increase the understanding of the complex mechanism of airway remodeling and provide a basis for novel treatments of asthma.

\section{Materials and methods}

Animal randomization and modeling. A total of 36 3-4-week-old female BALB/c mice were purchased from the Guangdong Medical Laboratory Animal Center (Foshan, China) and housed in 6 chambers ( 6 mice each) with a temperature of $24 \pm 3^{\circ} \mathrm{C}$, humidity $60 \pm 4 \%$, free access to food and water, and a 12-h light/dark cycle. Mice were divided into six groups (6 mice/group) using a random number table: group $\mathrm{C}$, control group; group A, asthma group; group T, transfection group; group $\mathrm{BC}$, blank control group; group $\mathrm{NC}$, negative control group; and group PC, positive control group.

On days $0,14,28$ and 42 , each mouse in group $\mathrm{C}$ was injected with $0.2 \mathrm{ml}$ saline into the abdomen, and each mouse in groups A, T, BC, NC and PC were injected with $0.2 \mathrm{ml}$ allergenic solution [10\% ovalbumin (OVA; Sigma-Aldrich, Merck KGaA, Darmstadt, Germany) $\left.+10 \% \mathrm{Al}(\mathrm{OH})_{3}\right]$. Between days 21 and 50 (3 times/week for 4 weeks), atomized saline was administered to the mice in group $\mathrm{C}$ and atomized $1 \%$ OVA was administered to the mice in the other groups for $30 \mathrm{mins}$ in a glass test container (30x15×20 cm; Fig. 1). Between days 50 and 64, the mice in group BC were administered $0.2 \mathrm{ml}$ atomized saline, and those in groups T, NC and PC were administered atomized transfection liquid, for 15 mins in a glass container every 2 days (Fig. 1). The atomized transfection liquid consisted of $40 \mu \mathrm{g}$ transfection DNA, $6 \mu \mathrm{l}$ transfection reagent (Polyplus-transfection SA, Illkirch, France) and $5 \mathrm{ml}$ $5 \%$ glucose solution. $\beta 1$ integrin shRNA, missense chain and GAPDH were used in groups T, NC and PC, respectively. All of the mice were sacrificed by cervical dislocation on the 67 th day. The flowchart of the establishment of the mouse model is presented in Fig. 1. The present study was approved by the Ethics Committee of Shenzhen People's Hospital (Shenzhen, China).

shRNA synthesis and vector construction/verification. According to the gene information for $\beta 1$ integrin in GenBank (no. NM_16412; www.ncbi.nlm.nih.gov/genbank), the 425th nucleotide in the gene encoding region was selected as the initial shRNA target point. Target gene sequences with a GC content between 40 and $55 \%$ were selected for potential optimization. Basic Local Alignment Search Tool (www.ncbi.nlm.nih.gov/blast) retrieval was used in the expressed sequence tag database in GenBank. The selected sequence and the corresponding genome database were compared to eliminate homology with other coding sequences and to determine specificity. The efficiencies of sequences in inhibiting the mRNA expression of $\beta 1$ integrin were assessed using the reverse transcription-quantitative polymerase chain reaction (RT-qPCR). The missense chain was also selected based on $\beta 1$ integrin gene. An siRNA against GAPDH was included as a positive control to verify transfection reliability, RNA extraction and gene expression quantification. All shRNA sequences used were as follows: $\beta 1$ integrin, 5'-CAC CGCAGGGCCAAATTGTGGGTTTCAAGAGAACCCACA ATTTGGCCCTGCTTTTTTG-3'; missense chain, 5'-CAC CGCAGGGCCAAATTGTGGGTTTCAAGAGAACCCACA ATTTGGCCCTGCTTTTTTG-3'; GAPDH, 5'-CACCGTATG ACAACAGCCTCAAGTTCAAGAGACTTGAGGCTGTTG TCATACTTTTTTG-3'.

Subsequent to connecting the carrier to the shRNA section, PCR and electrophoresis were performed. The recombinant positive clone fragments were subjected to sequencing by Guangzhou Genewiz Biotechnology (Guangzhou, China). The experiment also included missense chain as a negative control, and GAPDH as a positive control.

Specimen separation and collection. The left lung was ligated following separation of the trachea, bronchus and lung tissues. Tissue specimens were frozen in liquid nitrogen for subsequent RNA extraction. The right lung was perfused in $4 \%$ polyformaldehyde solution using a $24 \mathrm{G}$ indwelling needle. The right middle lobe was separated, ligated and preserved in $4 \%$ paraformaldehyde.

Hematoxylin and eosin staining and measurement of ASM thickness. The tissue was embedded in paraffin and sectioned at $4 \mu \mathrm{m}$. Sections were deparaffinized by immersion in xylene and dyed with hematoxylin for 3 mins at room temperature. Sections were washed three times in $\mathrm{ddH}_{2} \mathrm{O}$ and placed in $85 \%$ acid ethanol for 2 mins. The sections were subsequently dyed with eosin for 5 mins and dehydrated through graded alcohols (90, 80 and 70\%). The tissues were soaked in xylene, dried and the morphological alterations in the stained sections were examined.

A total of four different cross-sectional airway sections from each specimen were randomly selected to analyze under light microscopy (magnification, x200). ASM thickness was observed and measured. The ASM thickness of each specimen was calculated from the mean of the four airway cross-sections.

RNA extraction and RT-qPCR analysis. Total RNA was extracted from tissue specimens using TRIzol reagent (Invitrogen; Thermo Fisher Scientific, Inc., Waltham, MA, USA), according to the manufacturer's protocol. cDNA was generated using the PrimeScript ${ }^{\mathrm{TM}}$ RT reagent kit (DRR037A; Takara Biotechnology Co., Ltd., Dalian, China), and amplified first by PCR using the TaKaRa Ex Taq kit (RR001A; Takara Biotechnology Co., Ltd.) to screen the primers, which were designed using Primer 3 software, version 0.4.0 (23), based on data from Uniprot (www.uniprot.org). The thermocycling conditions for the PCR were $95^{\circ}$ for $30 \mathrm{sec}$ to activate the DNA polymerase, followed by 40 cycles of $95^{\circ} \mathrm{C}$ for $5 \mathrm{sec}, 55^{\circ} \mathrm{C}$ 


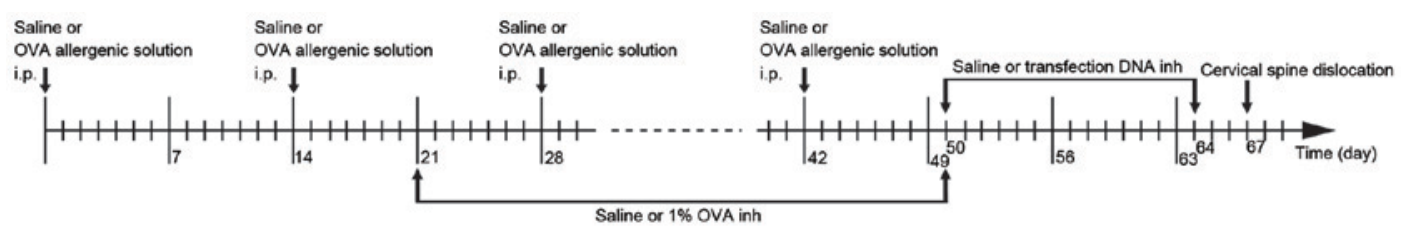

Figure 1. Flowchart of the establishment of the mouse model. i.p., intraperitoneal injection; inh, inhalation; OVA, ovalbumin.

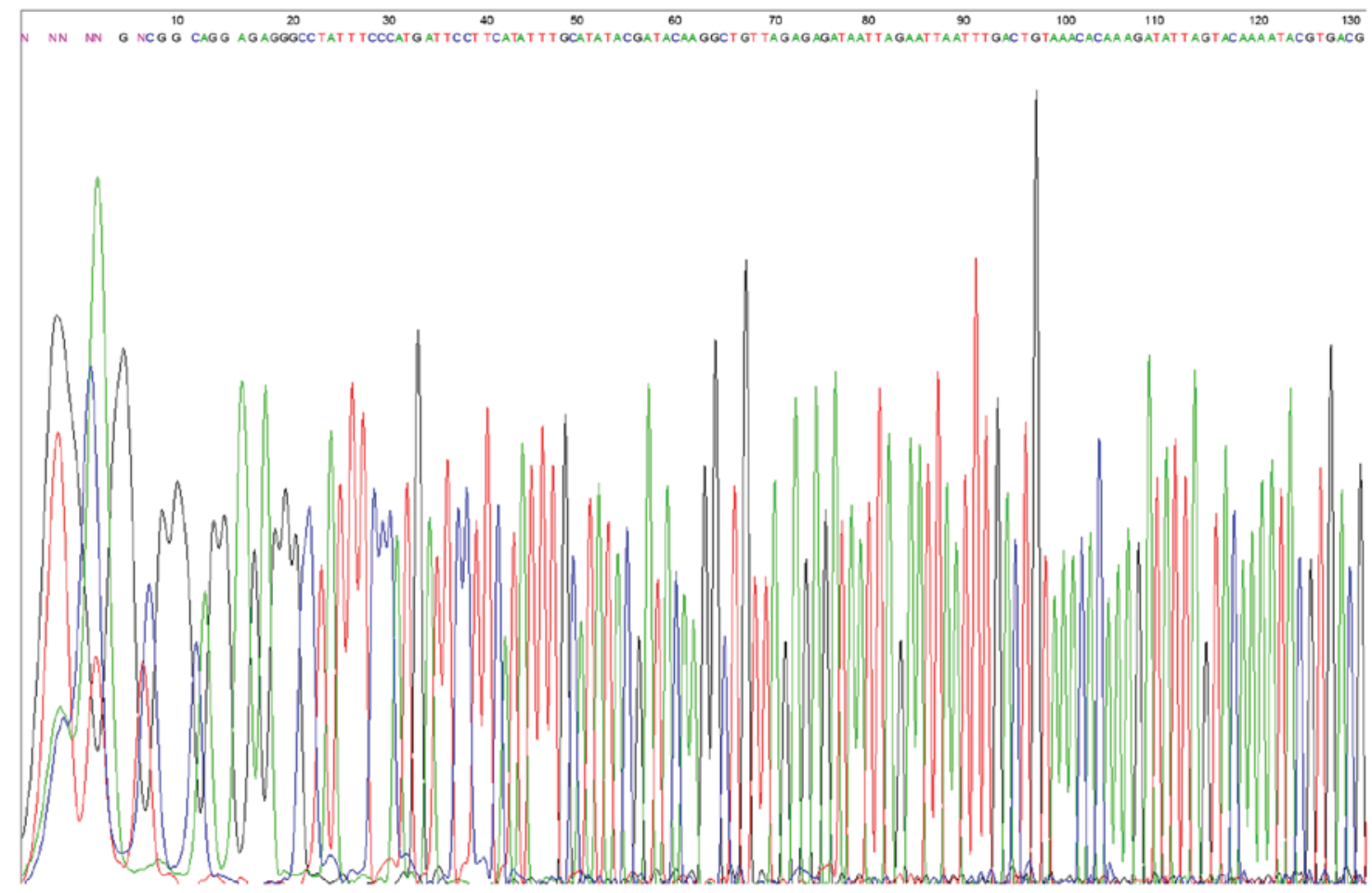

Figure 2. Identification of $\beta 1$ integrin short hairpin RNA vector.

for $30 \mathrm{sec}$ and $72^{\circ} \mathrm{C}$ for $30 \mathrm{sec}$. Melting curve analysis was performed to verify a single product without primer-dimers. The thermocycling conditions of qPCR were the same as above. qPCR was performed on an iQ5 system (Bio-Rad Laboratories, Inc., Hercules, CA, USA) using a SYBR Premix Ex Taq ${ }^{\text {TM }}$ II kit (DRR081A; Takara Biotechnology Co., Ltd.). qPCR results were analyzed using the $2^{-\Delta \Delta C q}$ method (24) and were normalized to $\beta$-actin. Primer sequences are presented in Table I.

ELISA analysis of IL-4 and interferon (IFN)- $\gamma$ levels in serum. Blood samples were placed in serum separator tubes, maintained at room temperature for $30 \mathrm{~min}$ and centrifuged for $15 \mathrm{~min}$ with $1,400 \mathrm{x}$ g at $25^{\circ} \mathrm{C}$. Serum was transferred into a $1.5-\mathrm{ml}$ centrifuge tube and stored at $4^{\circ} \mathrm{C}$. The levels of IFN- $\gamma$ and IL-4 in the serum samples were determined using mouse IFN- $\gamma$ kit DKW 12-2000 and IL-4 ELISA kit DKW12-2040 (Dakewe Biotech Co., Ltd., Shenzhen, China), respectively, in accordance with the manufacturers' protocol.

Statistical analysis. All data are presented as the mean \pm standard error of the mean. $\mathrm{P}<0.05$ was considered to indicate as statistically significant difference. All data represented the average of six replicate experiments. The
ASM thickness, RT-qPCR results, and IL-4 and IFN- $\gamma$ levels were analyzed using one-way analysis of variance followed by Student-Newman-Keuls post hoc tests. Statistical analysis was performed using GraphPad Prism (version 6.02; GraphPad Software, Inc., La Jolla, CA, USA).

\section{Results}

Identification of $\beta 1$ integrin shRNA vector. The results demonstrated that the restructured RNA interference vector fragments were all consistent with the synthesized target chain, which confirmed that the synthesized DNA oligo had been successfully inserted into the carrier for the construction of the shRNA vector (Fig. 2).

Assessment of the model and measurement of ASM thickness. Mice in group $\mathrm{C}$ did not exhibit tachypnea or other asthma symptoms. No pathological alterations in the structure of the airway wall were observed in the tissue sections from group C (Fig. 3A). Conversely, mice in group A exhibited tachypnea and mild cyanosis symptoms during OVA-induced asthma. Following continuous OVA-induced asthma, The fur of mice was lackluster in group A. The tissue sections demonstrated epithelial denudation with goblet cell metaplasia, increased 
Table I. Primers used in the present study.

\begin{tabular}{llllrr}
\hline Gene name & \multirow{2}{*}{ Gene ID } & \multicolumn{1}{c}{ Forward primer } & Reverse primer & Product size (bp) & E, $\%$ \\
\hline$\beta$ actin & A1E281 & AAGAGCTATGAGCTGCCTGA & GTTGAAGGTAGTTTCGTGGA & 159 & 98 \\
$\beta 1$ integrin & P09055 & TTCAGACTTCCGCATTGGCT & TGGAAAACACCAGCAGTCGT & 302 & 104 \\
$\alpha$-SMA & P62737 & CTCTGCCTCTAGCACACAACT & ACGCTCTCAAATACCCCGTTT & 333 & 96 \\
STIM1 & P70302 & GGTGGAGAAACTGCCTGACA & CAACTGGAGATGGCGTGTCT & 188 & 102 \\
ORAI1 & Q8BWG9 & CCACAACCTCAACTCGGTCA & AACTGCCGGTCCGTCTTATG & 351 & 89 \\
TRPC1 & Q61056 & AGTCCTTCGTTGGAGCTGTG & TGCCTTTCGAGGTATGCGAG & 276 & 103 \\
NFAT2 & Q60591 & ACCTGGCTTGGTAACACCAC & GGGCTGTCTTTCGAGACTTG & 135 & 96 \\
\hline
\end{tabular}

E, qPCR efficiency; $\alpha$-SMA, $\alpha$-smooth muscle actin; STIM1, stromal interaction molecule 1; ORAI1, calcium release-activated calcium modulator 1; TRPC1, short transient receptor potential channel member 1; NFAT2, nuclear factor of activated T-cells cytoplasmic 1.

A

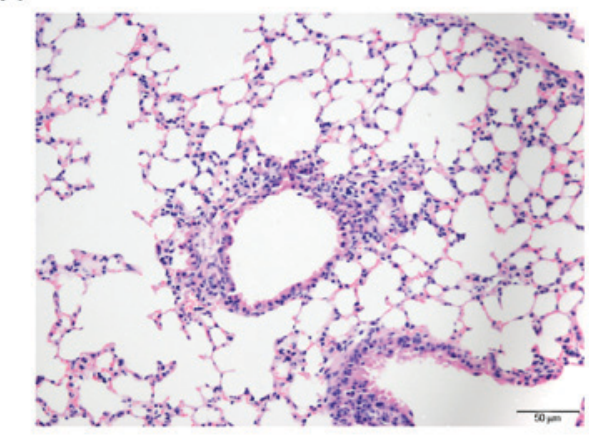

B

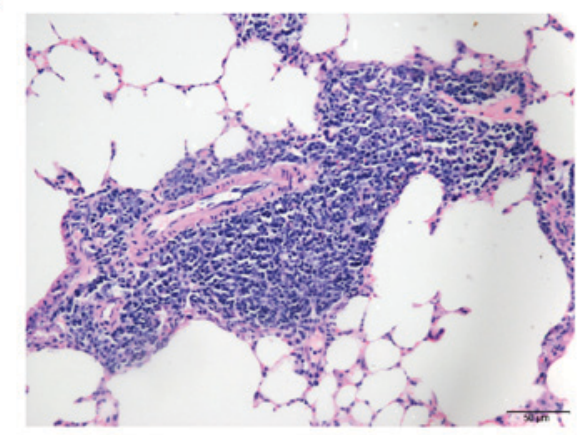

C

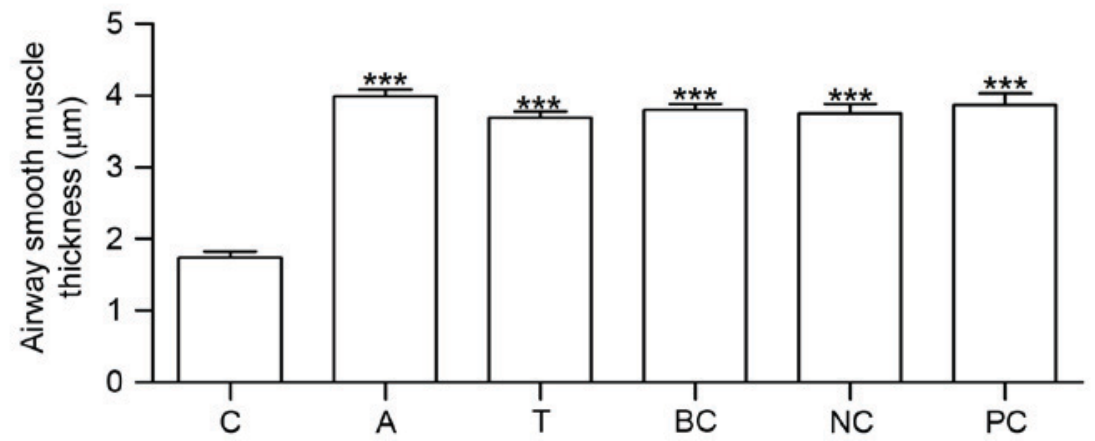

Figure 3. HE staining and measurement of airway smooth muscle thickness. Lung tissue sections were stained using HE. The morphological alterations in the stained sections were examined under microscopy. (A) HE staining in C. (B) HE staining in A. (C) Histogram exhibiting the increased airway smooth muscle thickness which occurred in $\mathrm{A}, \mathrm{T}, \mathrm{BC}, \mathrm{NC}$ and $\mathrm{PC} . \mathrm{n}=6{ }^{*}{ }^{* * *} \mathrm{P}<0.001$ vs. C. C, control group; A, asthma group; T, transfection group; $\mathrm{BC}$, blank control group; $\mathrm{NC}$, negative control group; PC, positive control group; HE, hematoxylin and eosin.

thickness of ASM and angiogenesis (Fig. 3B). Compared with group C, ASM thickness was increased in groups A, T, BC, $\mathrm{NC}$ and PC (Fig. 3C).

Silencing of $\beta 1$ integrin gene regulates the gene expression of SOCE-associated genes and nuclear factor of activated T-cells cytoplasmic 1 (NFAT2). The mRNA expression of six genes was measured in all of the groups, including $\beta 1$ integrin, $\alpha$-smooth muscle actin (SMA), three SOCE-associated genes (STIM1, ORAI1 and TRPC1) and NFAT2. Compared with group $\mathrm{C}$, the transcription of $\beta 1$ integrin, all of the SOCE-associated genes and $\alpha$-SMA was upregulated in groups
A, BC, NC and PC (Fig. 4). Additionally, the transcription of $\alpha$-SMA and STIM1 was upregulated in group T, in contrast with group C. A total of four genes did not exhibit significantly altered expression between groups $\mathrm{T}$ and $\mathrm{C}$, including $\beta 1$ integrin, ORAI1, TRPC1 and NFAT2 (Fig. 4).

Silencing the $\beta 1$ integrin gene regulates $I L-4$ and $I F N-\gamma$ expression levels. Cytokine IL-4 was increased in groups A, $\mathrm{BC}, \mathrm{NC}$ and $\mathrm{PC}$ compared with group C. Compared with group $\mathrm{C}$, IFN- $\gamma$ was downregulated in group A (Fig. 5). Neither IL-4 nor IFN- $\gamma$ exhibited significantly altered expression between groups $\mathrm{T}$ and $\mathrm{C}$ (Fig. 5). 
A

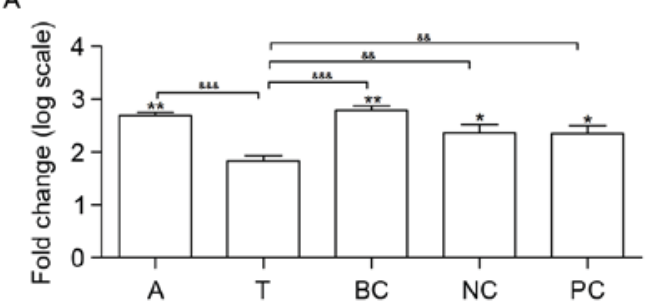

C

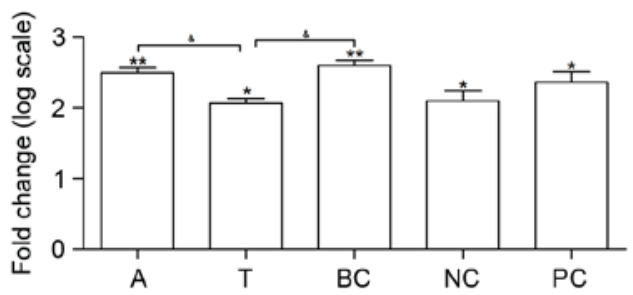

E

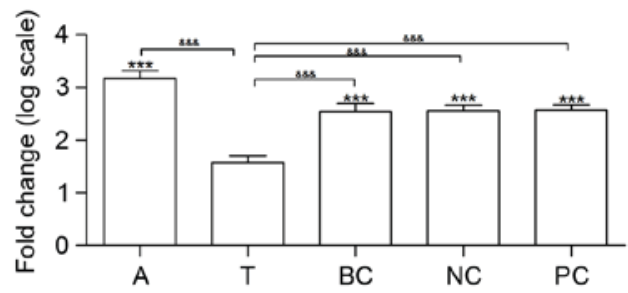

B

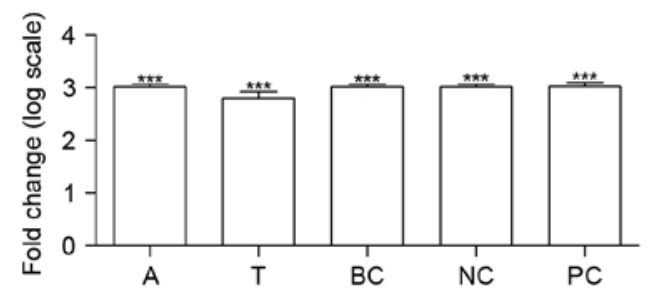

D

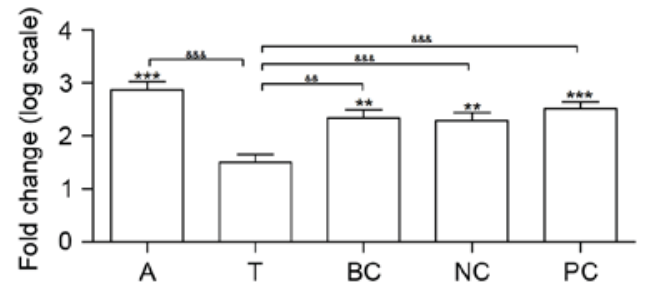

F

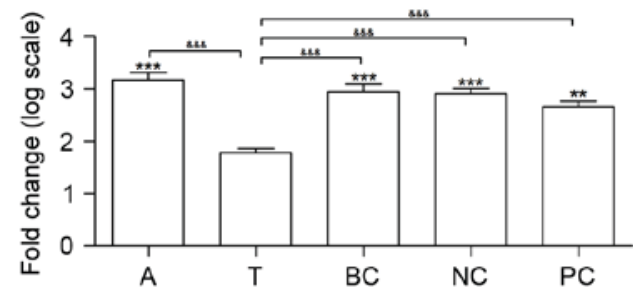

Figure 4. Effects of $\beta 1$ integrin short hairpin RNA on the expression of $\beta 1$ integrin, $\alpha$-SMA and SOCE signaling pathway genes in the lungs of mice. Silencing $\beta 1$ integrin affected six SOCE signaling pathway genes at the transcriptional level. The mRNA expression of (A) $\beta 1$ integrin, (B) $\alpha$-SMA, (C) STIM1, (D) ORAI1, (E) TRPC1 and (F) NFAT2 was measured. $\mathrm{n}=6 .{ }^{*} \mathrm{P}<0.05,{ }^{* *} \mathrm{P}<0.01$ and ${ }^{* * * *} \mathrm{P}<0.001$ vs. C. ${ }^{~} \mathrm{P}<0.05$, \&\& $\mathrm{P}<0.01$ and ${ }^{\text {\&\&\& }} \mathrm{P}<0.001$. C, control group; $\mathrm{A}$, asthma group; T, transfection group; BC, blank control group; NC, negative control group; PC, positive control group; SMA, smooth muscle actin; SOCE, store-operated $\mathrm{Ca}^{2+}$ entry; STIM1, stromal interaction molecule 1; ORAI1, calcium release-activated calcium modulator 1; TRPC1, short transient receptor potential channel member 1; NFAT2, nuclear factor of activated T-cells cytoplasmic 1.

A

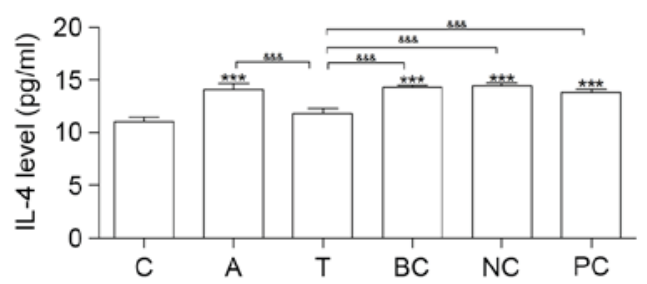

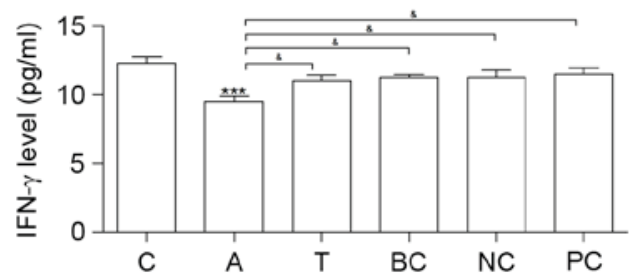

Figure 5. ELISA analysis. Results of the ELISA analysis of (A) IL-4 and (B) IFN- $\gamma$ expression levels. $\mathrm{n}=6 .{ }^{*} \mathrm{P}<0.05,{ }^{* *} \mathrm{P}<0.01$ and ${ }^{* * * *} \mathrm{P}<0.001$ vs. C. ${ }^{\text {\& }} \mathrm{P}<0.05$, ${ }^{\& \&} \mathrm{P}<0.01$ and ${ }^{\& \& \&} \mathrm{P}<0.001$. C, control group; A, asthma group; T, transfection group; BC, blank control group; NC, negative control group; PC, positive control group; IL-4, interleukin-4; IFN- $\gamma$, interferon- $\gamma$.

\section{Discussion}

The accumulation of $\beta 1$ integrin in ASM has been demonstrated to be associated with the degree of airway fibrosis, inflammation and hyperresponsiveness $(19,20)$. The present study demonstrated that silencing the $\beta 1$ integrin gene led to a downregulation of $\beta 1$ integrin mRNA, without statistically decreasing ASM thickness and $\alpha$-SMA gene expression, in OVA asthmatic mice. Additionally, silencing of the $\beta 1$ integrin gene was able to regulate the transcription of SOCE-associated genes at normal levels, including ORAI1, TRPC1 and NFAT2. Silencing of $\beta 1$ integrin was additionally able to maintain inflammatory cytokines at normal levels in OVA asthmatic mice, including IL-4 and IFN- $\gamma$. $\beta 1$ integrin shRNA was specifically combined with target $\beta 1$ integrin mRNA, causing enzymatic degradation of mRNA and thereby decreasing the expression of $\beta 1$ integrin in mice. The results of the present study demonstrated that the expression level of $\beta 1$ integrin was not significantly different among groups NC, BC and PC, indicating that the shRNA was able to silence $\beta 1$ integrin mRNA with high specificity. The present result may provide a foundation for follow-up studies of $\beta 1$ integrin-targeted intervention in asthma.

Altered expression of calcium channel-associated genes has been associated with airway remodeling in asthma $(10,11,25)$. The results of the present study demonstrated an increase in STIM1, ORAI1 and TRPC1 mRNA levels in the asthma group compared with the control group. STIM1 and ORAI1 
have been observed to be upregulated in ASMCs from asthmatic mice $(13,25)$. STIM1/ORAI1-mediated SOCE has been observed to be associated with ASMC proliferation (10). Further studies are required to investigate the expression of STIM1, ORAI1 and TRPC1 in ASMCs from patients with asthma.

Transcriptional modulation of SOC channel-associated genes may represent an important mechanism underlying airway remodeling. The knockdown of ORAI1 expression in synthetic rat ASMCs has been demonstrated to attenuate ASMC proliferation and migration (25). Zou et al (10) observed that suppressing the mRNA expression of STIM1 or ORAI1 with specific shRNA resulted in a decrease in SOCE and ASMC proliferation. The mRNA expression of TRPC1 was observed to be increased in proliferative ASMCs compared with growth-arrested cells by Sweeney et al (9). The results of the present study demonstrated that silencing $\beta 1$ integrin led to the downregulation of the SOCE-associated genes ORAI1 and TRPC1. Therefore, attenuating the proliferation of ASMCs by silencing $\beta 1$ integrin may be a promising therapeutic approach for the treatment of airway remodeling.

NFAT2 regulates the transcription of pro-inflammatory $\mathrm{T}$ cell cytokines (26). T and B cells from ORAI1 knockout mice have been demonstrated to exhibit impaired SOCE and CRAC function, resulting in decreased expression of cytokines IL-4 and IFN- $\gamma$ in $\mathrm{CD}^{+}$and $\mathrm{CD}^{+} \mathrm{T}$ cells (27). In the present study, upregulated expression of NFAT2 and IL-4, and downregulation of IFN- $\gamma$ expression, was observed in the asthma group compared with the control group.

CRAC signaling via SOCE activates NFAT transcription factors in addition to NFAT-promoted gene expression $(28,29)$. Inhibition of the CRAC channel was demonstrated to attenuate allergic inflammation in rats, and airway lymphocyte cytokine production in cells from patients with asthma, by Kaur et al (30). ORAI1-knockout mice were demonstrated to exhibit decreased $\mathrm{T}$ cell cytokine production by McCarl et al (27). In addition, $\mathrm{Ca}^{2+}$-signaling of $\mathrm{T}$ cells is mediated by the induction of $\left[\mathrm{Ca}^{2+}\right]_{\mathrm{i}}$ by $\beta 1$ integrin through increased $\mathrm{Ca}^{2+}$-influx (31). In the present study, it was noted that the silencing of $\beta 1$ integrin maintained the expression of NFAT2 and inflammatory cytokines IL-4 and IFN- $\gamma$ at normal levels. It may be hypothesized that silencing $\beta 1$ integrin may inhibit allergic inflammation by attenuating the transcription of SOCE-associated genes.

Bronchial hyperresponsiveness has been demonstrated to be associated with airway wall thickness in asthma (16). In addition, the expression of $\alpha$-SMA has been hypothesized to be an important indicator of airway remodeling in asthma (2). The present study demonstrated that ASM thickness and $\alpha$-SMA gene expression were increased in Group T, in contrast with Group C. The results of the present study indicated that silencing $\beta 1$ integrin was insufficient to maintain normal ASM thickness and $\alpha$-SMA gene expression in asthmatic mice. Previous studies have reported that a number of factors may influence ASM thickness (32,33). For example, Hou et al (32) reported that the anti-inflammatory factor high-mobility group box protein 1 decreased smooth muscle thickness in OVA asthmatic mice. It is hypothesized that silencing $\beta 1$ integrin may delay the ASMC proliferation and prolong the time of airway remodeling, without altering the final outcome.
Numerous signaling pathways may be simultaneously associated with the regulation of ASMC proliferation.

In conclusion, the results of the present study demonstrated that $\beta 1$ integrin serves a role in ASMC proliferation and airway remodeling. Therefore, silencing $\beta 1$ integrin may represent a novel target for drug design to attenuate airway remodeling in chronic asthma.

\section{Acknowledgements}

The present study was supported by the National Natural Science Foundation of China (Beijing, China; grant no. 81270074).

\section{References}

1. Bateman ED, Hurd SS, Barnes PJ, Bousquet J, Drazen JM, FitzGerald M, Gibson P, Ohta K, O'Byrne P, Pedersen SE, et al: Global strategy for asthma management and prevention: GINA executive summary. Eur Respir J 31: 143-178, 2008.

2. Slats AM, Janssen K, van Schadewijk A, van der Plas DT, Schot R, van den Aardweg JG, de Jongste JC, Hiemstra PS, Mauad T, Rabe KF and Sterk PJ: Expression of smooth muscle and extracellular matrix proteins in relation to airway function in asthma. J Allergy Clin Immunol 121: 1196-1202, 2008.

3. Mahn K, Ojo OO, Chadwick G, Aaronson PI, Ward JP and Lee TH: $\mathrm{Ca}(2+)$ homeostasis and structural and functional remodelling of airway smooth muscle in asthma. Thorax 65: 547-552, 2010.

4. Helli PB and Janssen LJ: Properties of a store-operated nonselective cation channel in airway smooth muscle. Eur Respir J 32: 1529-1539, 2008

5. Hendeles L, Hill M, Harman E, Moore P and Pieper J: Dose-response of inhaled diltiazem on airway reactivity to methacholine and exercise in subjects with mild asthma. Clin Pharmacol Ther 43: 387-392, 1988.

6. Hoppe M, Harman E and Hendeles L: The effect of inhaled gallopamil, a potent calcium channel blocker, on the late-phase response in subjects with allergic asthma. J Allergy Clin Immunol 89: 688-695, 1992.

7. Ann Twiss M, Harman E, Chesrown S and Hendeles L: Efficacy of calcium channel blockers as maintenance therapy for asthma. Br J Clin Pharmacol 53: 243-249, 2002.

8. Ohga K, Takezawa R, Yoshino T, Yamada T, Shimizu Y and Ishikawa J: The suppressive effects of YM-58483/BTP-2, a store-operated $\mathrm{Ca}^{2+}$ entry blocker, on inflammatory mediator release in vitro and airway responses in vivo. Pulm Pharmacol Ther 21: 360-369, 2008.

9. Sweeney M, McDaniel SS, Platoshyn O, Zhang S, Yu Y, Lapp BR, Zhao Y, Thistlethwaite PA and Yuan JX: Role of capacitative $\mathrm{Ca}^{2+}$ entry in bronchial contraction and remodeling. J Appl Physiol (1985) 92: 1594-1602, 2002.

10. Zou JJ,Gao YD, Geng S and Yang J:Role of STIM1/Orai1-mediated store-operated $\mathrm{Ca}^{2+}$ entry in airway smooth muscle cell proliferation. J Appl Physiol (1985) 110: 1256-1263, 2011.

11. Spinelli AM and Trebak M: Orai channel-mediated $\mathrm{Ca}^{2+}$ signals in vascular and airway smooth muscle. Am J Physiol Cell Physiol 310: C402-C413, 2016.

12. Peel SE, Liu B and Hall IP: A key role for STIM1 in store operated calcium channel activation in airway smooth muscle. Respir Res 7: 119, 2006

13. Peel SE, Liu B and Hall IP: ORAI and store-operated calcium influx in human airway smooth muscle cells. Am J Respir Cell Mol Biol 38: 744-749, 2008.

14. Ong HL, Cheng KT, Liu X, Bandyopadhyay BC, Paria BC, Soboloff J, Pani B, Gwack Y, Srikanth S, Singh BB, et al: Dynamic assembly of TRPC1-STIM1-Orail ternary complex is involved in store-operated calcium influx. Evidence for similarities in store-operated and calcium release-activated calcium channel components. J Biol Chem 282: 9105-9116, 2007.

15. Cheng KT, Liu X, Ong HL and Ambudkar IS: Functional requirement for Orail in store-operated TRPC1-STIM1 channels. J Biol Chem 283: 12935-12940, 2008.

16. Manuyakorn W: Airway remodelling in asthma: Role for mechanical forces. Asia Pac Allergy 4: 19-24, 2014. 
17. Teoh CM, Tam JK and Tran T: Integrin and GPCR crosstalk in the regulation of ASM contraction signaling in asthma. J Allergy (Cairo) 2012: 341282, 2012.

18. Lei L, Liu D, Huang Y, Jovin I, Shai SY, Kyriakides T, Ross RS and Giordano FJ: Endothelial expression of betal integrin is required for embryonic vascular patterning and postnatal vascular remodeling. Mol Cell Biol 28: 794-802, 2008.

19. Shi F, Qiu C, Qi H and Peng W: shRNA targeting $\beta 1$-integrin suppressed proliferative aspects and migratory properties of airway smooth muscle cells. Mol Cell Biochem 361: 111-121, 2012.

20. Bazan-Perkins B, Sánchez-Guerrero E, Vargas $M H$, Martínez-Cordero E, Ramos-Ramírez P, Alvarez-Santos M, Hiriart G, Gaxiola M and Hernandez-Pando R: Beta1-integrins shedding in a guinea-pig model of chronic asthma with remodelled airways. Clin Exp Allergy 39: 740-751, 2009.

21. Black JL, Panettieri RA Jr, Banerjee A and Berger P: Airway smooth muscle in asthma: Just a target for bronchodilation? Clin Chest Med 33: 543-558, 2012.

22. Fernandes DJ, Bonacci JV and Stewart AG: Extracellular matrix, integrins, and mesenchymal cell function in the airways. Curr Drug Targets 7: 567-577, 2006.

23. Rozen S and Skaletsky H: Primer3 on the WWW for general users and for biologist programmers. Methods Mol Biol 132: 365-386, 2000.

24. Livak KJ and Schmittgen TD: Analysis of relative gene expression data using real-time quantitative PCR and the 2(-Delta Delta C(T)) Method. Methods 25: 402-408, 2001.

25. Spinelli AM, González-Cobos JC, Zhang X, Motiani RK, Rowan S, Zhang W, Garrett J, Vincent PA, Matrougui K, Singer HA and Trebak M: Airway smooth muscle STIM1 and Orail are upregulated in asthmatic mice and mediate PDGF-activated SOCE, CRAC currents, proliferation and migration. Pflugers Arch 464: 481-492, 2012.
26. Macian F: NFAT proteins: key regulators of T-cell development and function. Nat Rev Immunol 5: 472-484, 2005.

27. McCarl CA, Khalil S, Ma J, Oh-hora M, Yamashita M, Roether J, Kawasaki T, Jairaman A, Sasaki Y, Prakriya M and Feske S: Store-operated $\mathrm{Ca}^{2+}$ entry through ORAI1 is critical for T cell-mediated autoimmunity and allograft rejection. J Immunol 185: 5845-5858, 2010.

28. Samanta K, Bakowski D and Parekh AB: Key role for store-operated $\mathrm{Ca}^{2+}$ channels in activating gene expression in human airway bronchial epithelial cells. PLoS One 9: e105586, 2014.

29. Gwack Y, Srikanth S, Feske S, Cruz-Guilloty F, Oh-hora M, Neems DS, Hogan PG and Rao A: Biochemical and functional characterization of Orai proteins. J Biol Chem 282: 16232-16243, 2007.

30. Kaur M, Birrell MA, Dekkak B, Reynolds S, Wong S, De Alba J, Raemdonck K, Hall S, Simpson K, Begg M, et al: The role of CRAC channel in asthma. Pulm Pharmacol Ther 35: 67-74, 2015.

31. Schottelndreier H, Mayr GW and Guse AH: Beta1-integrins mediate $\mathrm{Ca}^{2+}$-signalling and $\mathrm{T}$ cell spreading via divergent pathways. Cell Signal 11: 611-619, 1999.

32. Hou C, Kong J, Liang Y, Huang H, Wen H, Zheng X, Wu L and Chen Y: HMGB1 contributes to allergen-induced airway remodeling in a murine model of chronic asthma by modulating airway inflammation and activating lung fibroblasts. Cell Mol Immunol 12: 409-423, 2015.

33. Park CS, Bang BR, Kwon HS, Moon KA, Kim TB, Lee KY, Moon HB and Cho YS: Metformin reduces airway inflammation and remodeling via activation of AMP-activated protein kinase. Biochem Pharmacol 84: 1660-1670, 2012. 